\title{
尿液蛋白生物标志物验证时要考虑的因素
}

\author{
邭宇航, 秦伟伟, 高友鹤* \\ 北京师范大学生命科学学院, 北京 100875 \\ * 联系人, E-mail: gaoyouhe@bnu.edu.cn
}

收稿日期: 2017-08-16; 接受日期: 2017-09-26; 网络版发表日期: 2018-01-29

国家重点研发计划(批准号：2016YFC1306300)、国家重点基础研究发展计划(批准号：2013CB530805)、北京市自然科学基金(批准号： 7173264, 7172076)、中央高校基本科研专项资金(批准号: 2015KJJCB21)、北京市重点实验室建设基金(批准号: 110651103)、北京师范大 学科研启动基金和北京师范大学科研基金(批准号: 11100704)资助

\begin{abstract}
摘要生物标志物是和疾病相关的可监测的变化. 尿液因其不受人体稳态调节而比血液更富于变化, 是早 期、敏感的生物标志物来源. 尿液由于受到的各种因素的影响, 变化极其复杂, 一个排除这些影响的方法就是 在动物模型上控制其他影响因素, 单独观察每个应用因素的作用, 找到与疾病直接相关的尿液变化, 并且在选 择需要验证的疾病候选标志物时应该考虑是不是已经被发现受到一些常见因素的影响, 最后再在临床样本上 验证找到的尿液标志物线索与人类疾病的关系. 本文拟通过列表形式展示疾病候选标志物受影响因素(生理因 素、药理因素)影响的情况, 提示验证疾病候选标志物时应该慎重考虑这些蛋白, 减少验证的成本和精力, 以期 更有效地建立起人类疾病与其尿液标志物的相对特异的关系。
\end{abstract}

关键词尿液蛋白质组, 生理因素, 药理因素, 疾病标志物

生物标志物是与疾病相关的可监测的变化, 其本 质是变化 ${ }^{[1]}$. 血液是机体内环境的重要组成, 受稳态机 制的严格调节, 不易累积变化 ${ }^{[2]}$. 尿液是经血液过滤后 形成的代谢废物, 不受稳态机制调节, 能够富集机体 为维持稳态而排出的各种变化. 因此, 尿液比血液更 快、更灵敏地反映机体的变化, 是挖掘早期疾病标志 物的重要来源 ${ }^{[1,3]}$. 此外, 尿液还具有可无创、大量、 连续收集等优点.

尿液生物标志物研究, 其核心问题在于寻找生物 标志物与疾病之间的特异联系, 多肽、核酸、代谢产 物、细胞碎屑等都有可能成为生物标志物, 本文提及 的尿液生物标志物均为尿液蛋白质. 尿液蛋白质组受
多种因素影响, 包括性别、年龄等生理因素 ${ }^{[4]}$, 以及临 床用药的影响 ${ }^{[5]}$. 为此, 本研究组提出尿液生物标志物 研究路线图(图1): 在尽可能减少其他因素干扰的情况 下, 先在动物模型上 ${ }^{[6]}$ 找到在疾病发生发展过程中尿 液的变化, 然后再在临床样本上验证 ${ }^{[7]}$.一些受生理、 药理因素影响的候选疾病标志物在临床验证时会耗 费大量的成本和精力, 即使验证出与疾病相关, 将来 应用时也会受到这些因素干扰. 所以在临床验证之前, 应该排除受各种因素影响的候选标志物. 为了能更准 确特异地在尿液中确认出疾病的标志物, 先研究清楚 这些干扰因素单独存在时对尿的影响很有必要. 直接 找到线索的一个简单直接的方法是先通过动物模型.

引用格式: 狍宇航, 秦伟伟, 高友鹤. 尿液蛋白生物标志物验证时要考虑的因素. 中国科学: 生命科学, 2018, 48: 171-187

Huan Y H, Qin W W, Gao Y H. Factors to consider in the verification of urine biomarkers (in Chinese). Sci Sin Vitae, 2018, 48: 171-187, doi: 10.1360/ N052017-00157 


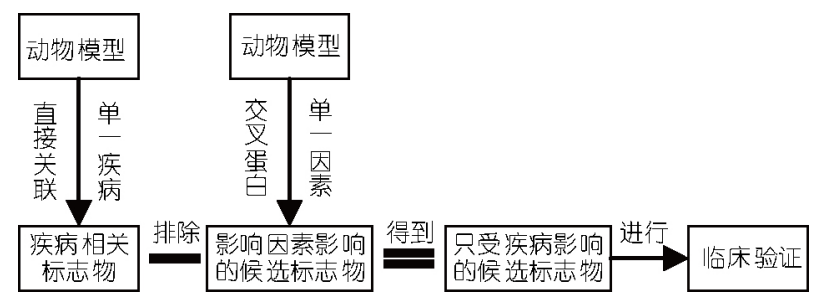

图 1 通过动物模型控制影响因素研究疾病标志物的方法

本文将动物模型中发现的疾病候选标志物(表1), 综合以往人体实验研究中发现的疾病候选标志物(网 络版附表1), 用列表展示既受生理、药理因素影响又 被报道为疾病标志物的蛋白信息, 为尿液生物标志物 的临床验证提供参考. 在尿液被严重忽视和低估的当 今医学界, 任何的相关研究都可能带来新的发现, 新 的理解, 都有助于矫正航线, 加快走向尿液生物标志 物的医学新时代.

\section{1 疾病模型}

通过在动物疾病模型上的研究发现, 尿液标志物 不仅可以反映与尿液直接关联的肾脏等器官的疾病, 在纤维化疾病、肿瘤、甚至脑膜炎等看似与尿液没有 直接关联的疾病中仍然得到了很有研究意义的结果, 尤其是在疾病早期标志物的寻找中有很大突破. 本文 选取了在动物模型上研究节段性肾小球硬化 ${ }^{[8]}$ 、单侧 输尿管梗阻 ${ }^{[9]}$ 、肝纤维化 ${ }^{[11]}$ 、肺纤维化 ${ }^{[14]}$ 、星状细胞 瘤 $^{[13]}$ 、Walker 256 皮下大鼠模型 ${ }^{[12]}$ 、细菌性脑膜炎 ${ }^{[10]}$ 这几种疾病的文章, 统计单一疾病影响时发现的人源 候选标志物, 并且在第2部分影响因素影响的蛋白中 检索, 得到的结果如表 1 所示. 可以看出确实有很多疾 病候选标志物受到不同生理、药理因素影响, 尤其是 同时受到 1 种以上其他因素影响的候选标志物, 在进 行下一步临床验证之前更要慎重考虑.

\section{1 节段性肾小球硬化}

通过对大鼠建立类似于人类发病的肾小球硬化模 型, 可以找到监测早期肾小球硬化的可靠生物标志物. 通过阿霉素诱导大鼠发病, 在病理切片上观察到发病 之前的 5 个时间节点收集尿样并用质谱(LC-MS/MS)检 测, 发现有 23 种蛋白随着疾病发生而显著差异表达, 有 20 种蛋白具有人类同源性, 其中有 13 种蛋白被鉴定 为正常人体尿液中稳定的蛋白质, 这也意味着这些蛋
白质的变化更有可能反映出肾小球硬化疾病的信息.

\section{2 单侧输尿管梗阻}

为了观测肾小管损伤及肾纤维化引起尿液蛋白质 组影响, 建立了大鼠单侧输尿管梗阻(unilateral ureteral obstruction, UOO)模型, 分别在模型建立后的第1周、 第3周收集尿样. 第1周时, 在病理切片观察中组织没有 发病症状, 应该为发病前期, 应用LC-MS/MS和Western 印迹检测发现有 7 种人源性的尿蛋白发生显著变化. 在第3 周时, 病理切片中可以看到有明显的肾小管萎 缩、肾小球破坏、间质显著增宽等现象, 此时可判断 为发病, 应用LC-MS/MS 和Western印迹检测发现有19 种人源性的尿蛋白发生了显著变化. 如果对这些差异 蛋白进行进一步验证, 理应得到指示输尿管梗阻的生 物标志物的更小范围.

\section{3 肝纤维化}

肝纤维化末期的肝硬化是不可逆转的恶性疾病, 所以在肝纤维化的大鼠模型中, 研究主要针对于肝纤 维化的非侵入性早期阶段, 在细胞外基质成分中寻找 生物标志物, 这时的病情是可以逆转的, 因此更利于 在临床诊断上应用. 应用硫代乙酰胺 (thioacetamide, TAA)诱发大鼠的肝纤维化, 分别在诱发后的 $1,3,6,8$ 周对其尿液应用(2DLC-MS/MS) 的液体质谱检测, 发 现有 40 种蛋白在发病前后具有显著差异, 具有人源性 的蛋白为 36 种, 其中有 15 种曾被报道过为肝纤维化、 肝硬化及相关疾病的生物标志物, 有 10 种曾被报道 过与肝纤维化的病理和机制相关. 最有意义的发现 是, 这些差异蛋白的发现在血液中丙氨酸氨基转移酶 (alanine transaminase, ALT)和天冬氨酸转氨酶(aspartate aminotransferase, AST)两种酶检测到变化之前, 同时也 在病理切片中发现肝纤维化之前. 因此对这些蛋白进 行影响因素的排除, 对得到早期肝纤维化的疾病标志 物有较大意义.

\section{4 肺纤维化}

特发性肺脏纤维化 (idiopathic pulmonary fibrosis, IPF) 是一种致死性的肺部疾病, 并且在纤维化晚期缺 少有效的治疗药物, 因此发现IPF早期诊断的生物标 志物具有重要的临床意义. 在博来霉素诱导的肺纤维 化大鼠模型中, 通过对大鼠尿液进行收集和进行液体 


\section{表 1 动物模型中发现的疾病候选标志物及其受影响因素影响情况}

\begin{tabular}{|c|c|c|c|}
\hline 疾病名称 & 差异蛋白 & 人源ID & 影响因素 \\
\hline 节段性肾小球硬化大鼠(Rattus norvegicus)模型 ${ }^{[8]}$ & Afamin $^{*}$ & P43652 & $\begin{array}{c}\text { 阿司匹林、抗凝剂肝素、 } \\
\text { 抗凝剂阿曲加班 }\end{array}$ \\
\hline 节段性肾小球硬化大鼠模型 ${ }^{[8]}$ & Kininogen-1* & $\mathrm{P} 01042$ & \\
\hline 节段性肾小球硬化大鼠模型 ${ }^{[8]}$ & Carboxylesterase $1^{*}$ & P23141 & \\
\hline 节段性肾小球硬化大鼠模型 ${ }^{[8]}$ & Ig gamma-4 chain $\mathrm{C}$ region ${ }^{*}$ & P01861 & \\
\hline 节段性肾小球硬化大鼠模型 ${ }^{[8]}$ & Plasminogen $^{*}$ & P00747 & $\begin{array}{l}\text { 利尿剂呋塞米、抗凝剂肝 } \\
\text { 素、抗凝剂阿曲加班 }\end{array}$ \\
\hline 节段性肾小球硬化大鼠模型 ${ }^{[8]}$ & $\begin{array}{l}\text { T-cell immunoglobulin and mucin } \\
\text { domain-containing protein } 1^{*}\end{array}$ & Q96D42 & \\
\hline 节段性肾小球硬化大鼠模型 ${ }^{[8]}$ & Cadherin- $2^{*}$ & P19022 & \\
\hline 节段性肾小球硬化大鼠模型 ${ }^{[8]}$ & Aggrecan core protein ${ }^{*}$ & Q6PID9 & \\
\hline 节段性肾小球硬化大鼠模型 ${ }^{[8]}$ & Beta-2-glycoprotein $1^{*}$ & P02749 & $\begin{array}{c}\text { 抗凝剂肝素、抗凝剂阿曲 } \\
\text { 加班、精氨酸加压素 }\end{array}$ \\
\hline 节段性肾小球硬化大鼠模型 ${ }^{[8]}$ & Kallikrein-1 ${ }^{*}$ & P06870 & $\begin{array}{l}\text { 戊巴比妥钠、水合氯醛、抗 } \\
\text { 凝剂肝素、利尿剂呋塞米 }\end{array}$ \\
\hline 节段性肾小球硬化大鼠模型 ${ }^{[8]}$ & Fetuin- $8^{*}$ & Q9UGM5 & \\
\hline 大鼠单侧输尿管梗阻模型 $[9]$ & Alpha-actinin-1 & 文献未提及 & \\
\hline 大鼠单侧输尿管梗阻模型 ${ }^{[9]}$ & Annexin A1 & 文献未提及 & 酒精、可乐 \\
\hline 大鼠单侧输尿管梗阻模型 ${ }^{[9]}$ & Cluster of Histone H1.4 & 文献未提及 & \\
\hline 大鼠单侧输尿管梗阻模型 ${ }^{[9]}$ & Cluster of Vimentin & 文献未提及 & \\
\hline 大鼠单侧输尿管梗阻模型 ${ }^{[9]}$ & Clusterin & 文献未提及 & \\
\hline 大鼠单侧输尿管梗阻模型 ${ }^{[9]}$ 、细菌性脑膜炎 ${ }^{[10]^{*}}$ & Complement component $\mathrm{C} 9$ & 文献未提及 & \\
\hline 大鼠单侧输尿管梗阻模型 ${ }^{[9]}$ & $\begin{array}{l}\text { Glycogen phosphorylase, } \\
\text { muscle form }{ }^{*}\end{array}$ & 文献未提及 & \\
\hline 大鼠单侧输尿管梗阻模型 ${ }^{[9]}$ & Golgi resident protein GCP60 & 文献未提及 & \\
\hline 大鼠单侧输尿管梗阻模型 ${ }^{[9]}$ & Ig gamma-1 chain $\mathrm{C}$ region & 文献未提及 & 抗凝剂阿曲加班 \\
\hline 大鼠单侧输尿管梗阻模型 ${ }^{[9]}$ & Moesin & 文献未提及 & \\
\hline 大鼠单侧输尿管梗阻模型 ${ }^{[9]}$ & Periaxin & 文献未提及 & \\
\hline 大鼠单侧输尿管梗阻模型 ${ }^{[9]}$ & Protein S100-A8 & 文献未提及 & \\
\hline 大鼠单侧输尿管梗阻模型 ${ }^{[9]}$ & Solute carrier family 12 member $7^{*}$ & 文献未提及 & \\
\hline 大鼠单侧输尿管梗阻模型 ${ }^{[9]}$ & $\begin{array}{l}\text { intraflagellar transport protein } \\
\qquad 172 \text { homolog }^{*}\end{array}$ & 文献未提及 & \\
\hline 大鼠单侧输尿管梗阻模型 ${ }^{[9]}$ & Protein $\mathrm{S} 100-\mathrm{A} 9^{*}$ & 文献末提及 & \\
\hline 大鼠单侧输尿管梗阻模型 ${ }^{[9]}$ & Serine protease inhibitor $\mathrm{A} 3 \mathrm{~N}$ & 文献未提及 & $\begin{array}{c}\text { 抗凝剂肝素、抗凝剂 } \\
\text { 阿曲加班、糖皮质激 } \\
\text { 素药物泼尼松 }\end{array}$ \\
\hline 大鼠单侧输尿管梗阻模型 ${ }^{[9]}$ & Transaldolase & 文献未提及 & \\
\hline 肝纤维化 ${ }^{[11]}$ & Uteroglobin* & P11684 & \\
\hline $\begin{array}{c}\text { 肝纤维化 }{ }^{[11]^{*}} \text { 、星状细胞瘤 }{ }^{[9]^{*}} \text { 、Walker 256皮下 } \\
\text { 大鼠模型 }{ }^{[12]} \text { 、细菌性脑膜炎 }{ }^{[10]^{*}}\end{array}$ & $\begin{array}{l}\text { Neutrophil gelatinase-associated } \\
\text { lipocalin }\end{array}$ & P80188 & \\
\hline
\end{tabular}




\begin{tabular}{|c|c|c|c|}
\hline 疾病名称 & 差异蛋白 & 人源ID & 影响因素 \\
\hline 肝纤维化 ${ }^{[11]}$ & D-dopachrome decarboxylase ${ }^{*}$ & P30046 & \\
\hline 肝纤维化 ${ }^{[11]}$ & Torsin-1A-interacting protein $2^{*}$ & Q8NFQ8 & \\
\hline 肝纤维化 ${ }^{[1]}$ 、节段性肾小球硬化大鼠模型 ${ }^{[8]}$ & Complement factor $\mathrm{D}^{*}$ & P00746 & \\
\hline 肝纤维化 ${ }^{[11]}$ & Protein disulfide-isomerase $\mathrm{A}^{*}$ & P30101 & \\
\hline 肝纤维化 ${ }^{[11]}$ & $\begin{array}{l}\text { Alpha/beta hydrolase } \\
\text { domain-containing protein } 14 \mathrm{~B}^{*}\end{array}$ & Q96IU4 & 水合氯醛 \\
\hline 肝纤维化 ${ }^{[11]}$ & Ribonuclease $4^{*}$ & P34096 & \\
\hline 肝纤维化 ${ }^{[11]}$ & $\begin{array}{c}\text { Mannan binding lectin-associated } \\
\text { serine protease } 2^{*}\end{array}$ & O00187 & \\
\hline 肝纤维化 ${ }^{[11]}$ & $\begin{array}{c}\text { 3-mercaptopyruvate } \\
\text { sulfurtransferase }(\mathrm{MST})^{*}\end{array}$ & P25325 & \\
\hline 肝纤维化 ${ }^{[11]}$ & Superoxide dismutase $[\mathrm{Cu}-\mathrm{Zn}]^{*}$ & P00441 & 水合氯醛 \\
\hline 肝纤维化 ${ }^{[11]}$ & Carbonic anhydrase $3^{*}$ & P07451 & \\
\hline $\begin{array}{c}\text { 肝纤维化 }{ }^{[11]} \text { 、节段性肾小球硬化大鼠模 } \\
\text { 型 }^{[8]} \text { 、细菌性脑膜炎 }{ }^{[10]}\end{array}$ & Serotransferrin ${ }^{*}$ & P02787 & 戊巴比妥钠 \\
\hline 肝纤维化 ${ }^{[1]}$ 、星状细胞瘤 ${ }^{[13]}$ & Ketohexokinase ${ }^{*}$ & P50053 & \\
\hline 肝纤维化 ${ }^{[11]}$ 、星状细胞瘤 ${ }^{[13]}$ & Protein DJ-1* & Q99497 & \\
\hline 肝纤维化 ${ }^{[11]}$ & Putative lysozyme C-2* & P61626 & \\
\hline $\begin{array}{c}\text { 肝纤维化 }{ }^{[11]} \text { 、星状细胞瘤 }{ }^{[13]} \text { 、节段性 肾小球硬 } \\
\text { 化大鼠模型 }{ }^{[8]} \text { 、细菌性脑膜炎 }{ }^{[10]}\end{array}$ & Serum albumin ${ }^{*}$ & P02768 & $\begin{array}{l}\text { 可乐、戊巴比妥钠、抗凝 } \\
\text { 剂肝素、抗凝剂阿曲加班 }\end{array}$ \\
\hline 肝纤维化 ${ }^{[11]}$ & Mesothelin $^{*}$ & Q13421 & \\
\hline 肝纤维化 ${ }^{[11]}$ 、星状细胞瘤 ${ }^{[13]}$ & Secreted phosphoprotein $24^{*}$ & Q13103 & \\
\hline 肝纤维化 ${ }^{[11]}$ & Thioredoxin $^{*}$ & P10599 & \\
\hline $\begin{array}{c}\text { 肝纤维化 }{ }^{[11]^{*}} \text { 、星状细胞瘤 }{ }^{[13]^{*}} \text { 、大鼠单 } \\
\text { 侧输尿管梗阻模型 }{ }^{[9]}\end{array}$ & $\begin{array}{l}\text { Extracellular superoxide dismutase } \\
\qquad[\mathrm{Cu}-\mathrm{Zn}]\end{array}$ & P08294 & \\
\hline 肝纤维化 ${ }^{[11]}$ & cystatin $\mathrm{C}^{*}$ & P01034 & \\
\hline 肝纤维化 ${ }^{[11]^{*}}$ 、大鼠单侧输尿管梗阻模型 ${ }^{[9]}$ & Lumican & P51884 & 糖皮质激素药物泼尼松 \\
\hline 肝纤维化 ${ }^{[11]}$ & Cathepsin $Z^{*}$ & Q9UBR2 & \\
\hline 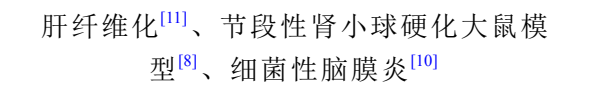 & Alpha-1-antiproteinase (A1AT) ${ }^{*}$ & P01009 & \\
\hline 肝纤维化 ${ }^{[11]}$ & cathepsin $\mathrm{L} 1^{*}$ & P07711/O60911 & \\
\hline 肝纤维化 ${ }^{[11]}$ 、细菌性脑膜炎 ${ }^{[10]}$ & Nidogen-2 ${ }^{*}$ & Q14112 & 可乐 \\
\hline 肝纤维化 ${ }^{[11]}$ & Cadherin-17 (CDH17) ${ }^{*}$ & Q12864 & \\
\hline 肝纤维化 ${ }^{[11]}$ 、节段性肾小球硬化大鼠模型 ${ }^{[8]}$ & CD166 antigen ${ }^{*}$ & Q13740 & $\begin{array}{c}\text { 可乐、糖皮质激素药 } \\
\text { 物泼尼松 }\end{array}$ \\
\hline $\begin{array}{c}\text { 肝纤维化 }{ }^{[11]^{*}} \text { 、肺纤维化 }{ }^{[14]} \text { 、节段性肾小 } \\
\text { 球硬化大鼠模型 }{ }^{[8]^{*}}\end{array}$ & Protein AMBP & P02760 & \\
\hline 肝纤维化 ${ }^{[11]}$ 、星状细胞瘤 ${ }^{[13]}$ & $\begin{array}{l}\text { Serine protease inhibitor } \mathrm{A} 3 \mathrm{M} \\
\text { (Fragment) }^{*}\end{array}$ & P01011 & $\begin{array}{l}\text { 抗凝剂阿曲加班、糖皮 } \\
\text { 质激素药物泼尼松 }\end{array}$ \\
\hline 肝纤维化 ${ }^{[11]^{*}} 、$ 肺纤维化 ${ }^{[14]}$ & Acidic mammalian chitinase & Q9BZP6 & \\
\hline 肝纤维化 ${ }^{[1]^{*}} 、$ Walker 256皮下大鼠模型 ${ }^{[12]}$ & Collectin-12 & Q5KU26 & \\
\hline
\end{tabular}




\begin{tabular}{|c|c|c|c|c|}
\hline & 疾病名称 & 差异蛋白 & 人源ID & 影响因素 \\
\hline & 肝纤维化 ${ }^{[11]}$ & $\begin{array}{l}\text { EGF-containing fibulin-like } \\
\text { extracellular matrix protein } 1^{*}\end{array}$ & Q12805 & \\
\hline & 肝纤维化 ${ }^{[11]}$ & $\begin{array}{l}\text { Multiple inositol polyphosphate } \\
\text { phosphatase } 1^{*}\end{array}$ & Q9UNW1 & \\
\hline & 肝纤维化 ${ }^{[11]}$ & Ephrin-B1 ${ }^{*}$ & P98172 & \\
\hline & 肺纤维化 ${ }^{[14]}$ & Prolactin-inducible protein homolog & P12273 & \\
\hline & 肺纤维化 ${ }^{[14]}$ & Abgiotensinogen & P01019 & \\
\hline & 肺纤维化 ${ }^{[14]}$ & Cysteine-rich secretory protein 1 & P54108 & \\
\hline & 肺纤维化 ${ }^{[14]}$ & $\begin{array}{l}\text { 4-hydroxyphenylpyruvate } \\
\text { dioxygenase }\end{array}$ & P32754 & \\
\hline & 肺纤维化 ${ }^{[14]}$ & Hemoglobin subunit alpha-1/2 & P69905 & 抗凝剂肝素 \\
\hline & 肺纤维化 ${ }^{[14]}$ & Parvalbumin alpha & P20472 & 可乐、水合氯醛 \\
\hline & 肺纤维化 ${ }^{[14]}$ & Ferritin light chain 1 & P02792 & \\
\hline & 肺纤维化 ${ }^{[14]}$ & $\begin{array}{c}\text { Serine protease inhibitor } \\
\text { Kazal-type } 3\end{array}$ & P00995 & \\
\hline & 肺纤维化 ${ }^{[14]}$ & Neural cell adhesion molecule 1 & P13591 & 糖皮质激素药物泼尼松 \\
\hline & 肺纤维化 ${ }^{[14]}$ & $\begin{array}{l}\text { Insulin-like growth factor-binding } \\
\text { protein } 3\end{array}$ & P17936 & 糖皮质激素药物泼尼松 \\
\hline 肺纤维化 ${ }^{[14]}$ 、 & 节段性肾小球硬化大鼠模型[8] & Alpha-2-HS-glycoprotein OS & P02765 & \\
\hline & 肺纤维化 ${ }^{[14]}$ & Selenoprotein P & P49908 & \\
\hline & 肺纤维化 ${ }^{[14]}$ & $\begin{array}{l}\text { Latent-transforming growth factor } \\
\text { beta-binding protein } 1\end{array}$ & Q14766 & \\
\hline & 肺纤维化 ${ }^{[14]}$ & $\begin{array}{l}\text { Phosphoinositide-3-kinase- } \\
\text { interacting protein } 1\end{array}$ & Q96FE7 & \\
\hline & 肺纤维化 ${ }^{[14]}$ & $\begin{array}{l}\text { WNT1-inducible-signaling } \\
\text { pathway protein } 1\end{array}$ & O95388 & \\
\hline & 肺纤维化 ${ }^{[14]}$ & Protein NOV homolog & P48745 & \\
\hline & 肺纤维化 ${ }^{[14]}$ & Fibulin-5 & Q9UBX5 & \\
\hline & 肺纤维化 ${ }^{[14]}$ & $\begin{array}{l}\text { Voltage-dependent anion-selective } \\
\text { channel protein } 1\end{array}$ & P21796 & \\
\hline & 肺纤维化 ${ }^{[14]}$ & Threonine synthase-like $2^{*}$ & Q86YJ6 & \\
\hline & 肺纤维化 ${ }^{[14]}$ & $\begin{array}{c}\text { Xin actin-binding repeat-containing } \\
\text { protein } 2(\mathrm{XIRP} 2)^{*}\end{array}$ & A4UGR9 & \\
\hline & 肺纤维化 ${ }^{[14]}$ & Vimentin $^{*}$ & $\mathrm{P} 08670$ & \\
\hline & 肺纤维化 ${ }^{[14]}$ & Protein RUFY3 ${ }^{*}$ & Q7L099 & \\
\hline & 肺纤维化 ${ }^{[14]}$ & Keratin, type II cytoskeletal $8^{*}$ & P05787 & \\
\hline & 肺纤维化 ${ }^{[14]}$ & $\begin{array}{l}\text { Low-density lipoprotein } \\
\text { receptor-related protein } 4^{*}\end{array}$ & O75096 & \\
\hline & 肺纤维化 ${ }^{[14]}$ & Stress-70 protein, mitochondrial ${ }^{*}$ & P38646 & \\
\hline
\end{tabular}




\begin{tabular}{|c|c|c|c|}
\hline 疾病名称 & 差异蛋白 & 人源ID & 影响因素 \\
\hline 肺纤维化 ${ }^{[14]}$ & $\begin{array}{l}\text { Ubiquitin carboxyl-terminal } \\
\text { hydrolase isozyme } \mathrm{L}^{*}\end{array}$ & P09936 & \\
\hline 星状细胞瘤 ${ }^{[13]^{*}}$ 、肺纤维化 ${ }^{[14]}$ & Uromodulin & P07911 & $\begin{array}{c}\text { 可乐、阿司匹林、戊巴 } \\
\text { 比妥钠、水合氯醛 }\end{array}$ \\
\hline 星状细胞瘤 ${ }^{[13]}$ & $\begin{array}{c}\text { Growth/differentiation factor } \\
15(\mathrm{GDF} 15)^{*}\end{array}$ & Q99988 & \\
\hline 星状细胞瘤 ${ }^{[13]}$ & Stanniocalcin- $1^{*}$ & P52823 & \\
\hline $\begin{array}{c}\text { 星状细胞瘤 } \\
{ }^{[12]} \text { 、细菌性脑膜炎 }{ }^{[10]}\end{array}$ & Haptoglobin(HPT) ${ }^{*}$ & P00739 & $\begin{array}{c}\text { 特异性 } \alpha 1 \text { - 肾上腺素能 } \\
\text { 受体拮抗剂哌唑嗪、利 } \\
\text { 尿剂螺内酯、糖皮质激 } \\
\text { 素药物泼尼松 }\end{array}$ \\
\hline $\begin{array}{c}\text { 星状细胞瘤 }{ }^{[13]} 、 \text { Walker } 256 \text { 皮下大鼠模型 } \\
{ }^{[12]} \text { 、细菌性脑膜炎 }{ }^{[10]}\end{array}$ & Alpha-1-acid glycoprotein ${ }^{*}$ & P02763 & 糖皮质激素药物泼尼松 \\
\hline $\begin{array}{c}\text { 星状细胞瘤 }{ }^{[13]^{*}} \text { 、肺纤维化 }{ }^{[14]} \text { 、节段性肾 } \\
\text { 小球硬化大鼠模型 }{ }^{[8]^{*}}\end{array}$ & Ceruloplasmin & P08571 & 抗凝剂阿曲加班 \\
\hline 星状细胞瘤 ${ }^{[13]}$ & Acyl-CoA-binding protein ${ }^{*}$ & P07108 & 糖皮质激素药物泼尼松 \\
\hline 星状细胞瘤 ${ }^{[13]}$ & Nucleobindin- $1^{*}$ & Q02818 & 水合氯醛 \\
\hline 星状细胞瘤[13] & Deoxyribonuclease- $1^{*}$ & P24855 & 抗凝剂肝素 \\
\hline 星状细胞瘤 ${ }^{[13]}$ & $\begin{array}{l}\text { Inter-alpha-trypsin B27inhibitor } \\
\text { heavy chain } \mathrm{H}^{*}\end{array}$ & Q06033 & \\
\hline 星状细胞瘤 ${ }^{[13]}$ & Aspartate aminotransferase ${ }^{*}$ & P17174 & \\
\hline 星状细胞瘤 ${ }^{[13]}$ & Hemoglobin subunit beta- $2^{*}$ & P68871 & \\
\hline 星状细胞瘤 ${ }^{[13]}$ & Hemoglobin subunit beta- $1^{*}$ & P68871 & 抗凝剂肝素 \\
\hline 星状细胞瘤 ${ }^{[13]}$ & $\begin{array}{c}\text { Ciliary neurotrophic factor receptor } \\
\text { subunit alpha }\end{array}$ & P26992 & \\
\hline 星状细胞瘤 ${ }^{[13]}$ & Sialidase- $1^{*}$ & Q99519 & \\
\hline 星状细胞瘤[13] & Prostatic steroid-binding protein $\mathrm{C} 1^{*}$ & O95968 & \\
\hline 星状细胞瘤 ${ }^{[13]}$ & Keratin, type I cytoskeletal $14^{*}$ & P02533 & \\
\hline 星状细胞瘤 ${ }^{[13]^{*}}$ 、肺纤维化 ${ }^{[14]}$ & $\begin{array}{c}\text { Pancreatic secretory granule } \\
\text { membrane major glycoprotein GP2 }\end{array}$ & P55259 & \\
\hline 星状细胞瘤 ${ }^{[13]}$ & Peroxiredoxin- $1^{*}$ & Q06830 & \\
\hline 星状细胞瘤 ${ }^{[13]}$ & Ribonuclease UK114* & P52758 & \\
\hline 星状细胞瘤 ${ }^{[13]}$ & Actin, alpha cardiac muscle $1^{*}$ & P68032 & \\
\hline 星状细胞瘤 ${ }^{[13]}$ 、大鼠单侧输尿管梗阻模型 ${ }^{[9]}$ & Cathepsin $\mathrm{D}^{*}$ & P07339 & \\
\hline 星状细胞瘤 ${ }^{[13]}$ & Ezrin $^{*}$ & P15311 & \\
\hline 星状细胞瘤 ${ }^{[13]}$ & Elongation factor 1 -alpha $1^{*}$ & P68104 & 抗凝剂阿曲加班 \\
\hline 星状细胞瘤 ${ }^{[13]}$ & Polyubiquitin-B ${ }^{*}$ & P0CG47 & \\
\hline 星状细胞瘤 ${ }^{[13]}$ & Phosphotriesterase-related protein ${ }^{*}$ & Q96BW5 & \\
\hline 星状细胞瘤 ${ }^{[13]}$ & Cofilin- $1^{*}$ & P23528 & \\
\hline 星状细胞瘤 ${ }^{[13]}$ & Ig kappa chain $\mathrm{C}$ region, $\mathrm{A}$ allele ${ }^{*}$ & P01834 & \\
\hline 星状细胞瘤 ${ }^{[13]}$ & Collectrin $^{*}$ & Q9HBJ8 & \\
\hline
\end{tabular}




\begin{tabular}{|c|c|c|c|}
\hline 疾病名称 & 差异蛋白 & 人源ID & 影响因素 \\
\hline 星状细胞瘤[13] & Glutamine synthetase ${ }^{*}$ & P15104 & \\
\hline 星状细胞瘤 ${ }^{[13]}$ & Neogenin (Fragment) ${ }^{*}$ & Q92859 & \\
\hline 星状细胞瘤 ${ }^{[13]}$ & Ketimine reductase mu-crystallin ${ }^{*}$ & Q14894 & \\
\hline 星状细胞瘤 ${ }^{[13]}$ & $\begin{array}{l}\text { Aflatoxin B1 aldehyde reductase } \\
\text { member } 3^{*}\end{array}$ & O95154 & \\
\hline 星状细胞瘤 ${ }^{[13]^{*}}$ 、大鼠单侧输尿管梗阻模型 ${ }^{[9]}$ & Alpha-actinin-4 & O43707 & \\
\hline 星状细胞瘤 ${ }^{[13]}$ & $\begin{array}{l}\text { Glyceraldehyde-3-phosphate } \\
\text { dehydrogenase, testis-specific }\end{array}$ & O14556 & \\
\hline 星状细胞瘤 ${ }^{[13]}$ & $\begin{array}{l}\mathrm{N} \text {-acyl-aromatic-L-amino acid } \\
\text { amidohydrolase }^{*}\end{array}$ & Q96HD9 & \\
\hline 星状细胞瘤 ${ }^{[13]}$ & Cytosolic non-specific dipeptidase ${ }^{*}$ & Q96KP4 & \\
\hline 星状细胞瘤 ${ }^{[13]}$ & C-reactive protein ${ }^{*}$ & P02741 & 抗凝剂阿曲加班 \\
\hline 星状细胞瘤 ${ }^{[13]}$ & Ester hydrolase $\mathrm{C} 11$ orf54 homolog ${ }^{*}$ & Q9H0W9 & \\
\hline 星状细胞瘤 ${ }^{[13]}$ & Fructose-1,6-bisphosphatase $1^{*}$ & P09467 & \\
\hline 星状细胞瘤 ${ }^{[13]}$ & $\begin{array}{l}\text { Isoamyl acetate-hydrolyzing } \\
\text { esterase } 1 \text { homolog }^{*}\end{array}$ & Q2TAA2 & \\
\hline 星状细胞瘤 ${ }^{[13]}$ & Nitrilase homolog $1^{*}$ & Q86X76 & \\
\hline 星状细胞瘤 ${ }^{[13]}$ & Meprin A subunit beta ${ }^{*}$ & Q16820 & 抗凝剂阿曲加班 \\
\hline 星状细胞瘤 ${ }^{[13]}$ & Calmodulin $^{*}$ & P62158 & \\
\hline 星状细胞瘤 ${ }^{[13]}$ & $\begin{array}{l}\text { Neuronal membrane glycoprotein } \\
\qquad \text { M6-a }^{*}\end{array}$ & P51674 & \\
\hline 星状细胞瘤 ${ }^{[13]}$ & Triosephosphate isomerase $^{*}$ & P60174 & \\
\hline 星状细胞瘤 ${ }^{[13]} 、$ 细菌性脑膜炎 ${ }^{[10]}$ & Prostatic spermine-binding protein ${ }^{*}$ & Q96DA0 & \\
\hline 星状细胞瘤 ${ }^{[13]^{*}}$ 、细菌性脑膜炎 ${ }^{[10]}$ & Complement $\mathrm{C} 3$ & P01024 & $\begin{array}{c}\text { 可乐、抗凝剂肝素、抗 } \\
\text { 凝剂阿曲加班 }\end{array}$ \\
\hline 星状细胞瘤 ${ }^{[13]}$ & Pyridoxal kinase $^{*}$ & O00764 & \\
\hline 星状细胞瘤 ${ }^{[13]}$ & Ig kappa chain $\mathrm{C}$ region, $\mathrm{B}$ allele ${ }^{*}$ & P01834 & \\
\hline 星状细胞瘤 ${ }^{[13]}$ & $\begin{array}{l}\text { Sodium-dependent phosphate } \\
\text { transport protein } 2 \mathrm{~A}^{*}\end{array}$ & Q06495 & \\
\hline 星状细胞瘤 ${ }^{[13]}$ & Tubulin beta-4B chain* & P68371 & \\
\hline 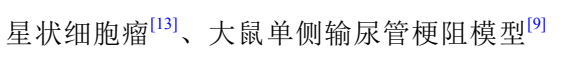 & Aminopeptidase $\mathrm{N}^{*}$ & $\mathrm{P} 15144$ & \\
\hline 星状细胞瘤 ${ }^{[13]}$ & Glutathione synthetase $^{*}$ & P48637 & \\
\hline 星状细胞瘤 ${ }^{[13]}$ & Regucalcin $^{*}$ & Q15493 & \\
\hline 星状细胞瘤 ${ }^{[13]}$ & Gamma-glutamyltran speptidase $1^{*}$ & P19440 & \\
\hline 星状细胞瘤 ${ }^{[13]}$ & $\begin{array}{l}\text { Solute carrier organic anion } \\
\text { transporter family member } 1 \mathrm{~A} 1^{*}\end{array}$ & P46721 & \\
\hline 星状细胞瘤 ${ }^{[13]}$ & $\begin{array}{l}\text { Glutamate--cysteine ligase } \\
\text { regulatory subunit }\end{array}$ & P48507 & \\
\hline 星状细胞瘤 ${ }^{[13]}$ & Cystathionine gamma-lyase $^{*}$ & P32929 & \\
\hline 星状细胞瘤[13] & Quinone oxidoreductase" & Q08257 & \\
\hline
\end{tabular}




\begin{tabular}{|c|c|c|c|}
\hline 疾病名称 & 差异蛋白 & 人源ID & 影响因素 \\
\hline 星状细胞瘤 ${ }^{[13]}$ & Actin, cytoplasmic $1^{*}$ & P60709 & 阿司匹林 \\
\hline 星状细胞瘤 ${ }^{[13]}$ & $\begin{array}{l}\text { Chloride intracellular channel } \\
\text { protein } 4^{*}\end{array}$ & Q9Y696 & \\
\hline 星状细胞瘤 ${ }^{[13]}$ & $\begin{array}{l}\text { Sodium-dependent neutral amino } \\
\text { acid transporter B (0) AT3 }{ }^{*}\end{array}$ & Q96N87 & \\
\hline 星状细胞瘤 ${ }^{[13]}$ & Glutathione S-transferase $\mathrm{P}^{*}$ & P09211 & 抗凝剂阿曲加班 \\
\hline 星状细胞瘤 ${ }^{[13]}$ & $\begin{array}{l}\text { Glutamate-cysteine ligase } \\
\text { catalytic subunit }^{*}\end{array}$ & P48506 & \\
\hline 星状细胞瘤 ${ }^{[13]}$ & Sulfotransferase $1 \mathrm{C} 2 \mathrm{~A}^{*}$ & O00338 & \\
\hline 星状细胞瘤 ${ }^{[13]}$ & Solute carrier family 23 member $1^{*}$ & Q9UHI7 & \\
\hline 星状细胞瘤 ${ }^{[13]}$ & Beta-glucuronidase ${ }^{*}$ & P08236 & \\
\hline 星状细胞瘤 ${ }^{[13]}$ & Adenosylhomocysteinase ${ }^{*}$ & P23526 & \\
\hline 星状细胞瘤 ${ }^{[13]}$ & $\begin{array}{l}\text { Chloride intracellular channel } \\
\text { protein } 1^{*}\end{array}$ & O00299 & \\
\hline 星状细胞瘤 ${ }^{[13]}$ & $\begin{array}{c}\mathrm{Na}^{+} / \mathrm{H}^{+} \text {exchange regulatory } \\
\text { cofactor }\end{array}$ & $\mathrm{O} 14745$ & \\
\hline 星状细胞瘤 ${ }^{[13]}$ & $\begin{array}{l}\text { ATP-binding cassette sub-family } \\
\qquad \mathrm{G} \text { member } 2^{*}\end{array}$ & Q9UNQ0 & \\
\hline 星状细胞瘤 ${ }^{[13]}$ & Neprilysin $^{*}$ & P08473 & 抗凝剂阿曲加班 \\
\hline 星状细胞瘤 ${ }^{[13]}$ & Deoxyribonuclease-2-beta $^{*}$ & Q8WZ79 & \\
\hline 星状细胞瘤 ${ }^{[13]}$ & Dihydropteridine reductase ${ }^{*}$ & P09417 & \\
\hline 星状细胞瘤 ${ }^{[13]}$ & $\begin{array}{l}\text { mitochondrial Kynurenine/alpha- } \\
\text { aminoadipate aminotransferase }\end{array}$ & Q8N5Z0 & \\
\hline 星状细胞瘤 ${ }^{[13]}$ & Aminoacylase-1 $\mathrm{A}^{*}$ & Q03154 & \\
\hline 星状细胞瘤 ${ }^{[13]}$ & Alkaline phosphatase ${ }^{*}$ & P05186 & \\
\hline 星状细胞瘤 ${ }^{[13]}$ & $\begin{array}{l}\mathrm{Na}^{+} / \mathrm{H}^{+} \text {exchange regulatory } \\
\text { cofactor NHE-RF3 }{ }^{*}\end{array}$ & Q5T2W1 & 可乐、水合氯醛 \\
\hline 星状细胞瘤 ${ }^{[13]}$ & Glutamyl aminopeptidase ${ }^{*}$ & Q07075 & \\
\hline 星状细胞瘤 ${ }^{[13]}$ & $\begin{array}{l}\text { Neutral and basic amino acid } \\
\text { transport protein } \text { BAAT }^{*}\end{array}$ & Q07837 & $\begin{array}{c}\text { 戊巴比妥钠、抗凝剂 } \\
\text { 阿曲加班 }\end{array}$ \\
\hline 星状细胞瘤 ${ }^{[13]}$ & Solute carrier family 7 member $13^{*}$ & Q8TCU3 & \\
\hline 星状细胞瘤 ${ }^{[13]}$ & EH domain-containing protein $1^{*}$ & Q9H4M9 & \\
\hline 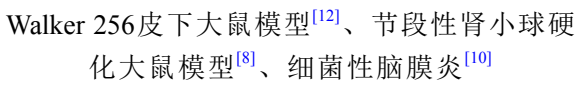 & Beta-2-microglobulin $(\mathrm{B} 2 \mathrm{MG})^{*}$ & P61769 & $\begin{array}{l}\text { 特异性 } \alpha 1-\text { 肾上腺素能受体 } \\
\text { 拮抗剂哌唑嗪、阿司匹林 }\end{array}$ \\
\hline Walker 256皮下大鼠模型 ${ }^{[12]^{*}}$ 、细菌性脑膜炎 ${ }^{[10]}$ & Complement $\mathrm{C} 4$ (CO4) & P0C0L4 & $\begin{array}{c}\text { 抗凝剂肝素、抗凝剂 } \\
\text { 阿曲加班、糖皮质激 } \\
\text { 素药物泼尼松 }\end{array}$ \\
\hline $\begin{array}{c}\text { Walker } 256 \text { 皮下大鼠模型 }{ }^{[12]} \text { 、大鼠单侧输尿管 } \\
\text { 梗阻模型 }\end{array}$ & Galectin-3-binding protein (LG3BP) & Q08380 & \\
\hline Walker 256皮下大鼠模型 ${ }^{[12]}$ 、细菌性脑膜炎 ${ }^{[10]^{*}}$ & T-kininogen 1 (KNT1) & P01042 & 抗凝剂阿曲加班 \\
\hline
\end{tabular}




\begin{tabular}{|c|c|c|c|}
\hline 疾病名称 & 差异蛋白 & 人源ID & 影响因素 \\
\hline Walker 256 皮下大鼠模型 ${ }^{[12]}$ & $\begin{array}{l}\text { Vascular cell adhesion protein } \\
\qquad 1(\text { VCAM } 1)^{*}\end{array}$ & P19320 & \\
\hline Walker 256 皮下大鼠模型 ${ }^{[12]}$ & Galectin-5 (LEG5) & Q6DKI2 & \\
\hline Walker 256皮下大鼠模型 ${ }^{[12]}$ & Galectin-9 (LEG9) & Q3B8N2 & \\
\hline Walker 256 皮下大鼠模型 ${ }^{[12]}$ & $\begin{array}{l}\text { Macrophage colony-stimulating } \\
\text { factor } 1(\mathrm{CSF} 1)\end{array}$ & P09603 & \\
\hline Walker 256 皮下大鼠模型 ${ }^{[12]}$ & Lithostathine (LITH) & P48304 & \\
\hline Walker 256 皮下大鼠模型 ${ }^{[12]}$ & $\begin{array}{c}\text { Programmed cell death 6-interacting } \\
\text { protein (PDC6I) }\end{array}$ & Q8WUM4 & \\
\hline Walker 256皮下大鼠模型 ${ }^{[12]}$ & Apolipoprotein A-IV (APOA4) ${ }^{*}$ & P06727 & \\
\hline Walker 256皮下大鼠模型 ${ }^{[12]}$ 、肺纤维化 ${ }^{[14]}$ & Calbindin (CALB1) ${ }^{*}$ & P05937 & \\
\hline Walker 256皮下大鼠模型 ${ }^{[12]}$ & Coagulation factor XII (FA12) & P00748 & \\
\hline Walker 256 皮下大鼠模型 ${ }^{[12]}$ & Vitamin D-binding protein (VTDB) ${ }^{*}$ & P02774 & 抗凝剂阿曲加班 \\
\hline Walker 256 皮下大鼠模型 ${ }^{[12]}$ 、细菌性脑膜炎 ${ }^{[10]^{*}}$ & Attractin (ATRN) & O75882 & \\
\hline Walker 256 皮下大鼠模型 ${ }^{[12]}$ & C-reactive protein (CRP) & P02741 & \\
\hline Walker 256 皮下大鼠模型 ${ }^{[12]}$ & Transcobalamin-2 (TCO2) & P20062 & \\
\hline Walker 256 皮下大鼠模型 ${ }^{[12]}$ & $\begin{array}{l}\text { Growth arrest-specific protein } \\
6 \text { (GAS6) }\end{array}$ & Q14393 & \\
\hline Walker 256 皮下大鼠模型 ${ }^{[12]}$ & $\begin{array}{c}\text { Alkaline phosphatase, } \\
\text { tissue-nonspecific isozyme (PРBT) }\end{array}$ & P05186 & \\
\hline Walker 256 皮下大鼠模型 ${ }^{[12]}$ & $\begin{array}{l}\text { Chondroitin sulfate proteoglycan } \\
\qquad 4 \text { (CSPG4) }\end{array}$ & Q6UVK1 & \\
\hline Walker 256皮下大鼠模型 ${ }^{[12]}$ 、肺纤维化 ${ }^{[14]^{*}}$ & Collagen alpha-1(I) chain (CO1A1) & P02452 & \\
\hline Walker 256皮下大鼠模型 ${ }^{[12]}$ & Anthrax toxin receptor 1 (ANTR1) & Q9H6X2 & \\
\hline Walker 256 皮下大鼠模型 ${ }^{[12]}$ & Dipeptidyl peptidase 1 (CATC) ${ }^{*}$ & P53634 & \\
\hline Walker 256 皮下大鼠模型 ${ }^{[12]}$ & Aggrecan core protein (PGCA) & $\mathrm{P} 16112$ & \\
\hline Walker 256皮下大鼠模型 ${ }^{[12]}$ & Tripeptidyl-peptidase 1 (TPP1) & O14773 & 糖皮质激素药物泼尼松 \\
\hline 细菌性脑膜炎 ${ }^{[10]}$ & Alpha-1-inhibitor $3^{*}$ & 文献未提及 & $\begin{array}{c}\text { 特异性 } \alpha 1 \text {-肾上腺素能 } \\
\text { 受体拮抗剂哌唑嗪、抗 } \\
\text { 凝剂阿曲加班、糖皮质 } \\
\text { 激素药物泼尼松 }\end{array}$ \\
\hline 细菌性脑膜炎 ${ }^{[10]}$ & Fibronectin ${ }^{*}$ & 文献未提及 & 抗凝剂阿曲加班 \\
\hline 细菌性脑膜炎 ${ }^{[10]}$ & Pro-epidermal growth factor ${ }^{*}$ & 文献未提及 & 阿司匹林、抗凝剂肝素 \\
\hline 细菌性脑膜炎 ${ }^{[10]}$ & $\begin{array}{l}\text { Matrix-remodeling-associated } \\
\text { protein } 8^{*}\end{array}$ & 文献未提及 & \\
\hline 细菌性脑膜炎 ${ }^{[10]}$ & Alpha-2HS-glycoprotein ${ }^{*}$ & 文献未提及 & \\
\hline 细菌性脑膜炎 ${ }^{[10]}$ & Glutathione S-transferase alpha-1 ${ }^{*}$ & 文献未提及 & \\
\hline 细菌性脑膜炎 ${ }^{[10]}$ & Apolipoprotein $\mathrm{M}^{*}$ & 文献未提及 & \\
\hline 细菌性脑膜炎 ${ }^{[10]}$ & Serine protease inhibitor $\mathrm{A} 3 \mathrm{~L}^{*}$ & 文献未提及 & \\
\hline 细菌性脑膜炎 ${ }^{[10]}$ & Alpha-1-macroglobulin ${ }^{*}$ & 文献未提及 & \\
\hline
\end{tabular}




\begin{tabular}{|c|c|c|c|}
\hline 疾病名称 & 差异蛋白 & 人源ID & 影响因素 \\
\hline 细菌性脑膜炎 ${ }^{[10]}$ & $\begin{array}{l}\text { Low-density lipoprotein } \\
\text { receptor-related protein } 2^{*}\end{array}$ & 文献未提及 & \\
\hline 细菌性脑膜炎 ${ }^{[10]}$ & Ceruloplasmin $^{*}$ & 文献未提及 & \\
\hline 细菌性脑膜炎 ${ }^{[10]}$ & Cathepsin $\mathrm{B}^{*}$ & 文献未提及 & \\
\hline 细菌性脑膜炎 ${ }^{[10]}$ & CD48 $_{\text {antigen }}{ }^{*}$ & 文献未提及 & \\
\hline 细菌性脑膜炎 ${ }^{[10]}$ & Protein FAM151A ${ }^{*}$ & 文献未提及 & \\
\hline 细菌性脑膜炎 ${ }^{[10]}$ & Cathepsin $\mathrm{S}^{*}$ & 文献未提及 & \\
\hline 细菌性脑膜炎 ${ }^{[10]}$ & Biglycan ${ }^{*}$ & 文献未提及 & \\
\hline 细菌性脑膜炎 ${ }^{[10]}$ & Putative phospholipase B-like $2^{*}$ & 文献未提及 & \\
\hline 细菌性脑膜炎 ${ }^{[10]}$ & Serine protease inhibitor $\mathrm{A} 3 \mathrm{M}$ & 文献未提及 & \\
\hline 细菌性脑膜炎 ${ }^{[10]}$ & Lysosomal alpha-glucosidase & 文献未提及 & \\
\hline 细菌性脑膜炎 ${ }^{[10]}$ & Carboxypeptidase Q & 文献未提及 & 阿司匹林、水合氯醛 \\
\hline
\end{tabular}

a) *标注为早期发现的疾病候选标志物, 如果蛋白同时在两种以上疾病中发现且不全为早期发现时*标注在相应疾病后

质谱(2DLC-MS/MS)检测, 在早期肺纤维化时发现 11 种差异蛋白, 其中有 4 种蛋白与纤维化的过程联系紧 密, 有9种具有人同源性, 在整个病程中发现 30 种差异 蛋白, 有 26 种具有人同源性, 可以进行肺纤维化疾病 的监测. 为了检测这些差异蛋白与肺纤维化发病机制 的关系, 文章中在疾病各个阶段采用糖皮质激素药物 泼尼松进行干预, 在早期效果显著, 在晚期没有明显 的作用效果, 早期的药物干预中有 5 种差异蛋白表达 趋势发生了逆转, 说明文章检测到的差异蛋白能够有 效地为肺纤维化发病早期诊断提供信息.

\section{5 星状细胞瘤}

作为最常见的侵袭性胶质瘤, 星状细胞瘤的早期 诊断目前还存在很大难题. 在星状细胞瘤的大鼠模 型中, 发现了尿液中一组敏感的蛋白, 有成为早期诊 断标志物的潜质. 将 C6 细胞注入Wistar大鼠中诱发星 状细胞瘤的形成, 在第 $2,6,10,13$ 天收集尿样后进行 LC-MS/MS检测, 发现差异蛋白随病情发展有所变化. 在第 10 天时通过磁共振成像发现了病变, 但是尿液中 的差异蛋白在第 2 天和第 6 天已经可以检测出来. 选取 第 2 天和第 6 天的 90 种具有人源性的显著差异表达的 蛋白进行影响因素的排除, 得到可以进行下一步验证 的早期疾病候选标志物.

\subsection{Walker 256皮下大鼠模型}

通过皮下注射Walker 256细胞建立Walker 256皮 下大鼠模型, 在癌细胞植入前、肿瘤确诊前、肿瘤大 量出现、肿瘤快速生长、肿瘤恶化这 5 个时间点收集 尿液进行检测, 通过靶向蛋白质组学及LC-MS/MS验 证, 发现有 29 种具有人源性的显著表达差异的蛋白可 作为诊断的候选标志物, 其中 10 种尿液蛋白在形成肿 瘤块之前就可以检测到, 对这29种蛋白进行影响因素 的排除同时, 尤其注意这 10 种蛋白可作为早期检测癌 症的敏感生物标志物.

\section{7 细菌性脑膜炎}

细菌性脑膜炎是引起新生儿和儿童疾病的重要 原因 ${ }^{[15]}$, 不仅死亡率特别高, 而且幸存者容易造成神经 系统的后遗症 ${ }^{[16]}$. 目前诊断的方法主要采用微生物培 养法, 但是这种方法灵敏度低 ${ }^{[17]}$, 早期难以应用. 为了 降低死亡率和致残率, 使用无创、简单的方法寻找细 菌性脑膜炎早期诊断的方式是十分必要的. 在大鼠细 菌性脑膜炎的研究中, 用感染大肠杆菌的大鼠模拟儿 童细菌性脑膜炎, 在术后第 1 天(疾病早期)和第3天(发 病期)分别收集尿样进行SDS-PAGE及LC-MS/MS 分析 发现, 早期尿液通过胶内酶切和膜上酶切鉴定出 30 种 差异蛋白, 发病期尿液通过膜上酶切鉴定出 5 种差异 
蛋白, 其中 33 种差异蛋白有人的同源蛋白. 这些结果 说明可以在尿液中找到脑部疾病相关的生物标志物, 尿液生物标志物在早期诊断中具有很大优势.

\section{2 影响因素}

在尿液疾病标志物的研究中, 如果受到除研究因 素以外的影响因素的干扰, 将会对标志物与疾病的特 异性建立、临床验证产生极大的干扰, 以本文引用的 影响因素对尿液蛋白质组影响的文章为基础, 发现包 含大量的已被报道过为疾病标志物的交叉蛋白, 检索 得到的结果如网络版附表1所示, 本文讨论的影响因 素分为生理因素与常见的临床用药两类.

\section{1 生理因素}

在临床诊断中, 生理因素个体差异很大且是无法 避免的无关变量, 研究表明具有不同遗传背景或有 地域差异的人尿液蛋白有很大差异, 男性女性各有 其性别依赖的蛋白 ${ }^{[18]}$, 女性由于周期性分泌的雌激素 变化也会引起尿液蛋白的变化 ${ }^{[19]}$. 随着年龄增长及 肾脏器官发育, 人体尿蛋白谱发生变化, 发现具有年 龄阶段特异性的蛋白 ${ }^{[20-22]}$. 鉴于目前在动物模型上研 究单一生理因素对尿液蛋白质组影响的文章很少, 在 生理因素上暂且参考人类样本中的研究. 本文讨论 的生理因素共10种: 性别 ${ }^{[18,20-27]}$ 、年龄 ${ }^{[20-22,28,29]}$ 、饮食 习惯 ${ }^{[30-36]}$ 、激素 ${ }^{[37 \sim 39]}$ 、日节律 ${ }^{[18,21,40,41]}$ 、锻炼 ${ }^{[42-50]}$ 、生 活方式 ${ }^{[51 ~ 58]}$ 、极端环境 ${ }^{[59,60]}$ 、遗传背景 ${ }^{[61,62]}$ 、身体质 量指数 ${ }^{[20,63]}$.

除此之外, 本文还选取了两篇摄入酒精 ${ }^{[64]}$ 、 可乐 ${ }^{[65]}$ 对大鼠尿蛋白质组影响的毕业论文. 统计大 鼠摄入可乐后变化显著的人源蛋白质中, 有 8 种蛋白 被确认与疾病有显著关系. 受酒精影响的蛋白中有 3 种与疾病标志物建立起关系.

从生理因素统计的结果中看出, 文章选取了多篇 研究人体生理因素对尿蛋白质影响的文章进行数据 检索, 如网络版附表1所示, 极少因素与报道过的疾病 标志物有关系, 而选取的仅两篇动物模型的文章均检 索出有与疾病标志物相交叉的蛋白, 在一定程度上说 明了动物模型的优势, 证明了建立动物模型、控制影 响因素研究的必要性.

\section{2 药理因素}

在尿液生物标志物的研究中, 应该充分考虑到药 物的影响作用 ${ }^{[5]}$. 如果没有考虑药物对尿蛋白质巨大 的影响而匀忙地在临床样本中进行验证, 会由于实验 设计失败而造成数据错误、大量资源的浪费 ${ }^{[66]}$. 基于 这种原则, 本文选取了多篇在动物模型中研究单一的 临床常用药物引起尿蛋白质组变化的文章, 发现了许 多与疾病标志物的交叉蛋白, 这些蛋白在今后的临床 验证之前就应该被注意到.

(1) 特异性 $\alpha 1$ - 肾上腺素能受体拮抗剂哌唑嗪. 为 了评估 $\alpha 1$ - 肾上腺素能受体对尿液蛋白质组影响, 应 用药物受体拮抗剂哌唑嗪并且建立大鼠动物模型进 行研究 ${ }^{[67]}$, 在鉴定出的 775 个蛋白质中, 约 $1 / 2$ 受到哌唑 嗪治疗的影响, 在显著变化的蛋白质中, 有 18 个具有 人类同源基因, 其中有 8 个曾被报道过为疾病标志物, $\alpha 1$-肾上腺素能受体已经证实会介导交感神经系统的 活动 ${ }^{[68]}$, 因此说明交感神经系统对尿蛋白质组变化有 显著影响. 同时, 哌唑嗪已被单独使用治疗心血管疾 病 ${ }^{[69]}$ 和创伤后应激障碍 ${ }^{[70]}$, 所以通过特异性拮抗剂来 理解 $\alpha 1$ - 肾上腺素能受体在尿液蛋白质组中起的作用 是有效的方式.

(2) 阿司匹林. 低剂量的阿司匹林在临床上被广泛 用于预防一些癌症的高危或低危患者的心肌梗死、 缺血性中风及血管性死亡 ${ }^{[71]}$, 此外, 最新研究表明阿司 匹林还可以降低癌症风险 ${ }^{[72]}$, 但是一些患者表现出血 小板聚集, 称为阿司匹林抵抗综合症 ${ }^{[73]}$, 因此监测其对 尿蛋白质组的影响并且通过尿液检测血液凝血状态 是必要的. 通过建立大鼠动物模型的研究 ${ }^{[74]}$ 发现, 受 阿司匹林显著影响的12种蛋白中, 有 9 种曾被报道过为 疾病的标志物, 说明阿司匹林确实对尿液蛋白质组有 不可忽略的影响. 实验中发现阿司匹林影响的蛋白质 和肝素、阿曲加班治疗 ${ }^{[75]}$ 引起的蛋白质不同, 说明尿 液蛋白质还可以区分不同凝血机制导致的凝血状态.

(3) 麻醉剂. 戊巴比妥钠和水合氯醛是动物实验 中常用的麻醉剂, 研究这两种麻醉剂对大鼠动物模型 尿蛋白质组的影响发现 ${ }^{[76]}$, 戊巴比妥钠麻醉后变化显 著的蛋白质中有 22 种, 其中有 11 种被标记为疾病标志 物, 有6种具有人同源基因, 水合氯醛麻醉后变化显著 的蛋白有 23 种, 其中被标记为疾病标志物的有 8 种, 有 12 种具有人同源基因. 两种麻醉剂虽然变化趋势不是 
很一致, 但是涉及的疾病多数为为脓毒诱发的急性肾 衰竭、肾小球疾病、单侧输尿管梗阻、肾范可尼综 合症(Fanconi syndrome, FS) 等肾脏疾病, 麻醉剂直接 作用的为神经系统, 所以这项研究也初步说明了肾脏 的处理功能可能与神经系统的调节有关系.

(4) 利尿剂. 通过评估 3 种常用利尿剂: 呋塞米、 螺内酯和氢氯噻嗪对大鼠尿蛋白质组的影响发现 ${ }^{[77]}$, 共有 14 种蛋白受到显著变化, 其中有 8 种蛋白有人同源 基因, 受呋塞米显著影响的 4 种人同源基因的蛋白质 中, 有3种蛋白被标记过疾病标志物; 受螺内酯显著影 响的 3 种人同源基因的蛋白质中, 均被标记过疾病标 志物; 受氢氯噻嗪影响的人同源基因的蛋白质仅有 1 种且未发现与疾病有显著影响关系, 从实验中可以得 到利尿剂对尿蛋白质有一定影响的结论, 也说明在研 究疾病时可以通过控制对尿液蛋白质组有不同影响 的实验用药, 来避免药理作用对相应疾病研究的影响.

(5) 抗凝剂. 通过评估两种常用的抗凝剂: 肝素和 阿曲加班对大鼠血浆及尿蛋白质组影响发现 ${ }^{[75]}$, 在肝 素治疗组中, 有 27 种尿液蛋白质发生显著变化, 只有 3 种蛋白质在血浆中发现了变化. 在阿曲加班治疗组 中, 有 62 种尿液蛋白质发生了显著变化, 仅有 1 种蛋白 质在血浆中检测到了变化, 再一次验证了尿液比血液 更敏感, 是更好的生物标志物来源. 通过对比几种药 物影响可以看出抗凝剂药物对尿蛋白质组的影响明 显高于其他几类药物, 阿曲加班的影响也明显高于肝 素的作用, 这说明了两种抗凝剂不同的凝血机制, 也 同样验证了在今后研究疾病中可以通过控制实验用 药的种类规避药理因素对尿蛋白质组的显著影响.

(6) 糖皮质激素泼尼松. 泼尼松是在治疗多种疾 病时常用的糖皮质激素, 研究泼尼松对大鼠尿蛋白质 组影响时发现 ${ }^{[78]}$, 有 32 种人同源基因的蛋白质受到此 药物显著影响, 其中被报道过为疾病标志物的有 17 种. 泼尼松涉及的疾病是本文所有药物中范围最广泛的, 原因是泼尼松强大的药理作用与蛋白质代谢有直接 的关系, 所以在研究尿液生物标志物过程中不能忽略 药理因素的影响, 同时结果也说明了尿蛋白质组有检 测药物药效的潜力.

(7) 精氨酸加压素. 精氨酸加压素 (argininevasopressin, AVP)又称精氨酸抗利尿激素, 作为一种常用的 临床用药, AVP有两个重要的生理功能: 血管收缩剂 和抗利尿剂 $\left[{ }^{[79]}\right.$, 参加多种生理过程包括生理压力 ${ }^{[80]}$ 、
体温调节 ${ }^{[81]}$ 、疼痛调节 ${ }^{[82]}$ 等, 在实际研究中AVP对尿 液蛋白质组的影响很难与相应疾病的影响区分, 因 此应该在动物模型中观察其影响力. 在大鼠模型研 究中发现 ${ }^{[83]}$, 给药前后共 17 种差异蛋白, 其中 16 种有 人类同源基因, 包含 9 种被标志过为疾病标志物的蛋 白, 说明AVP的研究价值, 文章同时还发现AVP有作为 抗利尿激素分泌失调综合征(syndrome of inappropriate antidiuretic hormone secretion, SIADH)标志物的潜力.

\section{3 小结}

根据单一疾病或单一影响因素作用前后尿液蛋 白丰度的变化, 可以找到在此因素下具有显著表达差 异的人源蛋白, 总结成表 1 (动物模型研究结果)、网 络版附表 1 (综合人类模型研究结果).

从表 1 中可以看出, 尿液中不仅可以找到泌尿系 统疾病的标志物, 也能找到肝纤维化、肺纤维化、星 状细胞瘤、皮下Walker256肿瘤, 甚至脑膜炎疾病的相 关变化. 尿液生物标志物对疾病早期监测也有重要意 义. 在动物模型实验结束后选择疾病候选标志物时, 应首先排除受影响因素影响的蛋白再进行下一步验 证, 例如, 在研究节段性肾小球硬化疾病时, 通过动物 模型发现有 20 种有显著差异表达的人源性的蛋白, 其 中有9种蛋白受到文中的影响因素影响, 所以应该优 先排除这 9 种蛋白, 对剩余 11 种蛋白进行下一步的验 证. 此外, 表中 7 种动物疾病模型均发现有各自的疾病 候选标志物受一种及多种影响因素的影响. 其中有 45 种疾病候选标志物受生理、药理因素影响, 有 20 种疾 病候选标志物受两种及以上生理、药理因素的影响, 这些蛋白在特异性方面应该被慎重考虑, 尤其是受多 种影响因素影响的蛋白, 在实验设计时应该尽量避免 这些生理、药理因素的作用, 在得到候选标志物、进 行下一步验证之前, 应该排除这些对疾病特异性程度 不高的蛋白. 网络版附表 1 中展示的是既被报道为疾 病标志物又受生理、药理因素影响的尿液蛋白, 这些 交叉因素影响的蛋白提示研究者们应该在今后的验 证及实验设计中充分考虑到影响因素对尿液生物标 志物的影响.

检索尿液生物标志物数据时发现, 目前在动物疾 病模型上的研究仍然很少, 在动物模型上单独研究生 理、药理因素作用的实验更少. 在动物模型的选择上, 


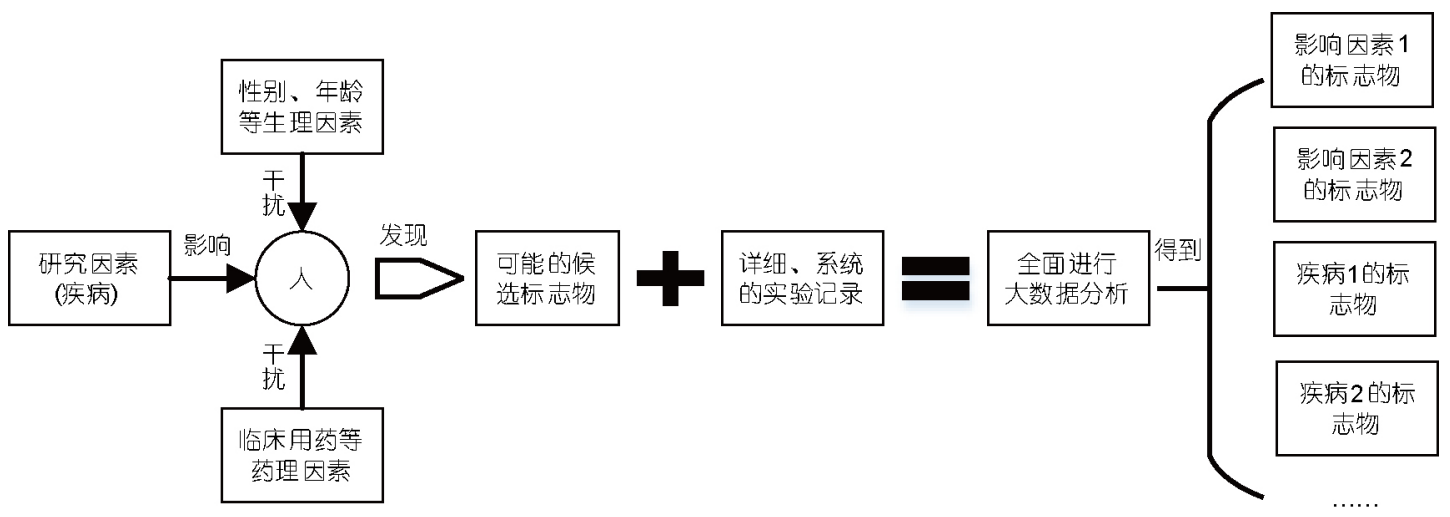

图 2 通过人体实验和大数据分析研究疾病标志物的方法

研究者们多选择大鼠模型. 在今后的研究中应该不断 完善单一疾病或单一影响因素对尿液蛋白质组的影 响的信息, 还应该选择不同的动物疾病模型, 研究同 一疾病条件下不同动物模型的尿液生物标志物的异 同, 以期得到更全面的分析.

\section{4 展望}

大数据思想在当今社会包括科学界都非常流行. 大数据分析的研究思路(图2): 以临床样本为研究对 象, 考虑所有干扰因素(性质和程度), 采集足够大的样 本, 通过大量的实验、计算, 把每一个干扰因素造成 的影响分析清楚, 以此来寻找与疾病相关的变化, 即 疾病标志物. 但是这一思路需要大量的投入, 只有前 期设计合理, 充分考虑所有或者至少是主要影响因素,
在疾病引起的变化比较突出的情况下, 也是一条可以 尝试的途径.

生物标志物与生理和病理生理紧密联系, 其最核 心的关键词是变化. 发现疾病标志物最重要的步骤就 是找到与疾病直接相关的相对特异的变化, 即不受生 理、药理因素影响或者受疾病影响显著大于生理、 药理因素的标志物. 通过本文综述结果显示(表1、网 络版附表1), 很多疾病候选标志物同时受生理、药理 因素影响. 为避免在大规模临床验证中成本和时间的 损失, 未来在生物标志物的研究中应该不断完善这些 交叉蛋白的信息. 现在对影响因素的认识还非常不足, 研究也太少. 本综述希望提醒更多学者、临床医生、 生物技术公司、基金会、风险投资人等各个方面, 注 意到尿液生物标志物发展过程中需要关注的这些问 题, 让尿液生物标志物的时代更早到来.

致谢感谢北京师范大学生命科学学院盛李、唐坤玉的毕业论文为本文章提供数据的支持; 感谢本课题组刘永 涛、李育秋对本文创作的帮助.

\section{参考文献}

1 高友鹤. 尿液有可能成为生物标志物的金矿吗? 中国科学: 生命科学, 2013, 43: 708

2 Cannon W B. Organization for physiological homeostasis. Physiol Rev, 1929, 9: 399-431

3 Thongboonkerd V, McLeish K R, Arthur J M, et al. Proteomic analysis of normal human urinary proteins isolated by acetone precipitation or ultracentrifugation. Kidney Int, 2002, 62: 1461-1469

4 Wu J, Gao Y. Physiological conditions can be reflected in human urine proteome and metabolome. Expert Rev Proteomics, 2015, 12: 623-636

5 Gao Y. Are urinary biomarkers from clinical studies biomarkers of disease or biomarkers of medicine? MOJ Proteomics Bioinform, 2014, in press, doi: 10.15406/mojpb.2014.01.00028

6 Gao Y. Are human biomarker studies always more valuable than animal ones? MOJ Proteomics Bioinform, 2015, in press, doi: 10.15406/mojpb.2015.02.00035 
7 Gao Y. Roadmap to the Urine Biomarker Era. MOJ Proteomics Bioinform, 2014, in press, doi: 10.15406/mojpb.2014.01.00005

8 Zhao M, Li M, Li X, et al. Dynamic changes of urinary proteins in a focal segmental glomerulosclerosis rat model. Proteome Sci, 2014, 12: 42

9 Yuan Y, Zhang F, Wu J, et al. Urinary candidate biomarker discovery in a rat unilateral ureteral obstruction model. Sci Rep, 2015, 5: 9314

10 倪艳颖, 张繁霜, 安满霞, 等. 细菌性脑膜炎大鼠模型的尿液蛋白质组学变化. 生物工程学报, 2017, 33: 1-13

11 Zhang F, Ni Y, Yuan Y. Early urinary candidate biomarker discovery in a rat thioacetamide-induced liver fibrosis model. bioRxiv, 2017, in press, doi: $10.1101 / 125120$

12 Wu J, Guo Z, Gao Y. Early biomarker discovery in urine of Walker 256 subcutaneous rat model. bioRxiv, 2017, in press, doi: 10.1101/114611

13 Ni Y, Zhang F, An M, et al. Early candidate biomarkers found from urine of astrocytoma rat before changes in MRI. bioRxiv, 2017, in press, doi: $10.1101 / 117333$

$14 \mathrm{Wu}$ J, Li X, Gao Y. Early detection in urinary proteome for the effective early treatment of bleomycin-induced pulmonary fibrosis in a rat model. Available from: http://www.paper.edu.cn, doi: 10.13140/RG.2.2.15793.99689

15 Wijetunge D S S, Karunathilake K H E M, Chaudhari A, et al. Complete nucleotide sequence of pRS218, a large virulence plasmid, that augments pathogenic potential of meningitis-associated Escherichia coli strain RS218. BMC Microbiol, 2014, 14: 203

16 Kim K S. Acute bacterial meningitis in infants and children. Lancet Infect Dis, 2010, 10: 32-42

17 Wu H M, Cordeiro S M, Harcourt B H, et al. Accuracy of real-time PCR, Gram stain and culture for Streptococcus pneumoniae, Neisseria meningitidis and Haemophilus influenzae meningitis diagnosis. BMC Infect Dis, 2013, 13: 26

18 Sun W, Chen Y, Li F, et al. Dynamic urinary proteomic analysis reveals stable proteins to be potential biomarkers. Prot Clin Appl, 2009, 3: $370-382$

19 Castagna A, Olivieri O, Milli A, et al. Female urinary proteomics: new insight into exogenous and physiological hormone-dependent changes. Prot Clin Appl, 2011, 5: 343-353

20 Kochhar S, Jacobs D M, Ramadan Z, et al. Probing gender-specific metabolism differences in humans by nuclear magnetic resonance-based metabonomics. Anal Biochem, 2006, 352: 274-281

21 Slupsky C M, Rankin K N, Wagner J, et al. Investigations of the effects of gender, diurnal variation, and age in human urinary metabolomic profiles. Anal Chem, 2007, 79: 6995-7004

22 Psihogios N G, Gazi I F, Elisaf M S, et al. Gender-related and age-related urinalysis of healthy subjects by NMR-based metabonomics. NMR Biomed, 2008, 21: 195-207

Oh J, Pyo J H, Jo E H, et al. Establishment of a near-standard two-dimensional human urine proteomic map. Proteomics, 2004, 4: 3485-3497 iTRAQ quantification. PLoS ONE, 2015, 10: e0133270

25 Becker L, Kheirandish-Gozal L, Peris E, et al. Contextualised urinary biomarker analysis facilitates diagnosis of paediatric obstructive sleep apnoea. Sleep Med, 2014, 15: 541-549

26 Mamtimin B, Mian Q, Chen C, et al. Gender related metabonomic analysis of serum and urine samples from Xinjiang healthy Han subjects with magnetic resonance. Med Sci, 2012, 37: 1135-1140

27 Zheng H, Yde C C, Arnberg K, et al. NMR-based metabolomic profiling of overweight adolescents: an elucidation of the effects of inter-/intraindividual differences, gender, and pubertal development. Biomed Res Int, 2014, 2014: 1-10

$28 \mathrm{Gu} \mathrm{H}$, Pan Z, Xi B, et al. 'H NMR metabolomics study of age profiling in children. NMR Biomed, 2009, 22: 826-833

29 Collino S, Montoliu I, Martin F P J, et al. Metabolic signatures of extreme longevity in northern italian centenarians reveal a complex remodeling of lipids, amino acids, and gut microbiota metabolism. PLoS ONE, 2013, 8: e56564

30 Li M, Zhao M, Gao Y. Effect of transient blood glucose increases after oral glucose intake on the human urinary proteome. Prot Clin Appl, 2015, 9: $618-622$

31 Wallner-Liebmann S, Gralka E, Tenori L, et al. The impact of free or standardized lifestyle and urine sampling protocol on metabolome recognition accuracy. Genes Nutr, 2015, 10: 441

32 Zheng H, Yde C C, Clausen M R, et al. Metabolomics investigation to shed light on cheese as a possible piece in the french paradox puzzle. J Agric Food Chem, 2015, 63: 2830-2839

33 Medina S, Ferreres F, García-Viguera C, et al. Non-targeted metabolomic approach reveals urinary metabolites linked to steroid biosynthesis pathway after ingestion of citrus juice. Food Chem, 2013, 136: 938-946

34 May D H, Navarro S L, Ruczinski I, et al. Metabolomic profiling of urine: response to a randomised, controlled feeding study of select fruits and vegetables, and application to an observational study. Br J Nutr, 2013, 110: 1760-1770

35 Llorach R, Medina S, García-Viguera C, et al. Discovery of human urinary biomarkers of aronia-citrus juice intake by HPLC-q-TOF-based 
metabolomic approach. Electrophoresis, 2014, 35: 1599-1606

36 Garcia-Aloy M, Llorach R, Urpi-Sarda M, et al. Novel multimetabolite prediction of walnut consumption by a urinary biomarker model in a free-living population: the PREDIMED study. J Proteome Res, 2014, 13: 3476-3483

37 Pinto J, Barros A S, Domingues M R M, et al. Following healthy pregnancy by NMR metabolomics of plasma and correlation to urine. J Proteome Res, 2015, 14: 1263-1274

38 Diaz S O, Barros A S, Goodfellow B J, et al. Following healthy pregnancy by nuclear magnetic resonance (NMR) metabolic profiling of human urine. J Proteome Res, 2013, 12: 969-979

39 Trivedi D K, Iles R K. HILIC-MS-based shotgun metabolomic profiling of maternal urine at 9-23 weeks of gestation-establishing the baseline changes in the maternal metabolome. Biomed Chromatogr, 2015, 29: 240-245

40 Lenz E M, Bright J, Wilson I D, et al. A ${ }^{1} \mathrm{H}$ NMR-based metabonomic study of urine and plasma samples obtained from healthy human subjects. J Pharmaceut Biomed Anal, 2003, 33: 1103-1115

41 Saccenti E, Tenori L, Verbruggen P, et al. Of monkeys and men: a metabolomic analysis of static and dynamic urinary metabolic phenotypes in two species. PLoS ONE, 2014, 9: e106077

42 Kohler M, Franz S, Regeniter A, et al. Comparison of the urinary protein patterns of athletes by 2D-gel electrophoresis and mass spectrometryâ a pilot study. Drug Test Anal, 2009, 1: 382-386

43 Kohler M, Walpurgis K, Thomas A, et al. Effects of endurance exercise on the urinary proteome analyzed by 2-D PAGE and Orbitrap MS. Prot Clin Appl, 2010, 4: 568-576

44 Pechlivanis A, Kostidis S, Saraslanidis P, et al. 'H NMR-based metabonomic investigation of the effect of two different exercise sessions on the metabolic fingerprint of human urine. J Proteome Res, 2010, 9: 6405-6416

45 Enea C, Seguin F, Petitpas-Mulliez J, et al. ${ }^{1} \mathrm{H}$ NMR-based metabolomics approach for exploring urinary metabolome modifications after acute and chronic physical exercise. Anal Bioanal Chem, 2010, 396: 1167-1176

46 Neal C M, Hunter A M, Brennan L, et al. Six weeks of a polarized training-intensity distribution leads to greater physiological and performance adaptations than a threshold model in trained cyclists. J Appl Physiol, 2013, 114: 461-471

47 Krug S, Kastenmüller G, Stückler F, et al. The dynamic range of the human metabolome revealed by challenges. FASEB J, 2012, 26: 2607-2619

48 Mukherjee K, Edgett B A, Burrows H W, et al. Whole blood transcriptomics and urinary metabolomics to define adaptive biochemical pathways of high-intensity exercise in 50-60 year old masters athletes. PLoS ONE, 2014, 9: e92031

49 Sheedy J R, Gooley P R, Nahid A, et al. ${ }^{1} \mathrm{H}-\mathrm{NMR}$ analysis of the human urinary metabolome in response to an 18-month multi-component exercise program and calcium-vitamin- $\mathrm{D}_{3}$ supplementation in older men. Appl Physiol Nutr Metab, 2014, 39: 1294-1304

50 Daskalaki E, Blackburn G, Kalna G, et al. A study of the effects of exercise on the urinary metabolome using normalisation to individual metabolic output. Metabolites, 2015, 5: 119-139

51 Airoldi L, Magagnotti C, Iannuzzi A R, et al. Effects of cigarette smoking on the human urinary proteome. Biochem Biophys Res Commun, 2009, 381: 397-402

52 Haniff A N, Gam L H. Identification of urinary protein biomarkers for tobacco smoking. Biotech Appl Biochem, 2016, 63: 266-272

53 Bouwman F G, de Roos B, Rubio-Aliaga I, et al. 2D-electrophoresis and multiplex immunoassay proteomic analysis of different body fluids and cellular components reveal known and novel markers for extended fasting. BMC Med Genomics, 2011, 4: 24

54 Alfadda A A, Turjoman A A, Moustafa A S, et al. A proteomic analysis of excreted and circulating proteins from obese patients following two different weight-loss strategies. Exp Biol Med (Maywood), 2014, 239: 568-580

55 Rothwell J A, Fillâtre Y, Martin J F, et al. New biomarkers of coffee consumption identified by the non-targeted metabolomic profiling of cohort study subjects. PLoS ONE, 2014, 9: e93474

56 Gibbons H, McNulty B A, Nugent A P, et al. A metabolomics approach to the identification of biomarkers of sugar-sweetened beverage intake. Am J Clin Nutr, 2015, 101: 471-477

57 Vazquez-Fresno R, Llorach R, Alcaro F, et al. ${ }^{1}$ H-NMR-based metabolomic analysis of the effect of moderate wine consumption on subjects with cardiovascular risk factors. Electrophoresis, 2012, 33: 2345-2354

58 Rubio-Aliaga I, de Roos B, Duthie S J, et al. Metabolomics of prolonged fasting in humans reveals new catabolic markers. Metabolomics, 2011, 7: $375-387$

59 Pastushkova L K, Kireev K S, Kononikhin A S, et al. Detection of renal tissue and urinary tract proteins in the human urine after space flight. PLoS ONE, 2013, 8: e71652

60 Lou B S, Wu P S, Liu Y, et al. Effects of acute systematic hypoxia on human urinary metabolites using LC-MS-based metabolomics. High Altitude Med Biol, 2014, 15: 192-202 
61 Lenz E M, Bright J, Wilson I D, et al. Metabonomics, dietary influences and cultural differences: a ${ }^{1} \mathrm{H}$ NMR-based study of urine samples obtained from healthy British and Swedish subjects. J Pharmaceut Biomed Anal, 2004, 36: 841-849

62 Dumas M E, Maibaum E C, Teague C, et al. Assessment of analytical reproducibility of ${ }^{1} \mathrm{H}$ NMR spectroscopy based metabonomics for large-scale epidemiological research: the INTERMAP study. Anal Chem, 2006, 78: 2199-2208

63 Xiao Q, Moore S C, Boca S M, et al. Sources of variability in metabolite measurements from urinary samples. PLoS ONE, 2014, 9: e95749

64 盛李. 酒精对大鼠尿蛋白质组的影响. 学士学位论文. 北京: 北京师范大学, 2016

65 Gao Y. Effects of Cola on the Rats' Urine Proteome. MOJ Proteomics Bioinform, 2016, in press, doi: 10.15406/mojpb.2016.04.00122

66 Gao Y. Medication needs to be considered in biomarker discovery. J Transl Proteomics Res, 2014, 1: 1

67 Zhao M, Wu J, Gao Y. The specific $\alpha 1$-adrenergic receptor antagonist prazosin influences the urine proteome. PLoS ONE, 2016, 11: e0164796

68 Piascik M T, Perez D M. Alpha1-adrenergic receptors: new insights and directions. J Pharmacol Exp Therapeut, 2001, 298: 403-410

69 Brogden R, Heel R, Speight T, et al. Prazosin: A Review of its Pharmacological Properties and Therapeutic Efficacy. Berlin: Springer, 1979. 125-169

70 Togno J, Eaton S. Is there a role for prazosin in the treatment of post-traumatic stress disorder? Austr Family Phys, 2015, 44: 647-649

71 Shao C, Li M, Li X, et al. A tool for biomarker discovery in the urinary proteome: a manually curated human and animal urine protein biomarker database. Mol Cell Proteomics, 2011, 10: M111.010975

72 Ciccolini F, Svendsen C N. Fibroblast growth factor 2 (FGF-2) promotes acquisition of epidermal growth factor (EGF) responsiveness in mouse striatal precursor cells: identification of neural precursors responding to both EGF and FGF-2. J Neurosci, 1998, 18: 7869-7880

73 Glanville R W, Qian R Q, McClure D W, et al. Calcium binding, hydroxylation, and glycosylation of the precursor epidermal growth factor-like domains of fibrillin-1, the Marfan gene protein. J Biol Chem, 1994, 269: 26630-26634

74 Gao Y. Effect of low-dose aspirin on candidate biomarkers in the urine proteome. MOJ Proteomics Bioinform, 2016, in press, doi: 10.15406/mojpb.2016.03.00087

75 Li M L, Zhao M D, Gao Y H. Changes of proteins induced by anticoagulants can be more sensitively detected in urine than in plasma. Sci China Life Sci, 2014, 57: 649-656

76 Zhao M, Li X, Li M, et al. Effects of anesthetics pentobarbital sodium and chloral hydrate on urine proteome. PeerJ, 2015, 3: e813

77 Li X, Zhao M, Li M, et al. Effects of three commonly-used diuretics on the urinary proteome. Genomics Proteomics Bioinformatics, 2014, 12: $120-126$

$78 \mathrm{Wu}$ J, Li X, An M, et al. Effects of the glucocorticoid drug prednisone on urinary proteome and candidate biomarkers. bioRxiv, 2017, in press, doi: $10.1101 / 128603$

79 Kounin G, Bashir Q. Mechanism and role of antidiuretic hormone. Surg Neurol, 2000, 53: 508-510

80 Coverdill A J, McCarthy M, Bridges R S, et al. Effects of chronic central arginine vasopressin (AVP) on maternal behavior in chronically stressed rat dams. Brain Sci, 2012, 2: 589-604

81 Bicego-Nahas K C, Steiner A A, Carnio E C, et al. Antipyretic effect of arginine vasotocin in toads. Am J Physiol Regul Integr Comp Physiol, 2000, 278: R1408-R1414

82 Madrazo I, Franco-Bourland R E, Leon-Meza V M, et al. Intraventricular somatostatin-14, arginine vasopressin, and oxytocin: analgesic effect in a patient with intractable cancer pain. Appl Neurophysiol, 1987, 50: 427-431

83 An M, Ni Y, Li X, et al. Effects of arginine vasopressin on the urine proteome in rats. PeerJ, 2017, 5: e3350 


\title{
Factors to consider in the verification of urine biomarkers
}

\author{
HUAN YuHang, QIN WeiWei \& GAO YouHe \\ School of Life Sciences, Beijing Normal University, Beijing 100875, China
}

\begin{abstract}
A biomarker is a measurable change associated with disease. Urine is a source of early, sensitive biomarkers because it is not under homeostatic control; therefore, changes occur more rapidly in urine than in blood. The composition of urine is affected by a variety of factors, and urine is susceptible to complex changes. A way to exclude the impact of multiple factors is to use an animal model in which control over all experimental factors is possible and to observe each factor separately. Additionally, some common effective factors should be considered when choosing disease candidate markers. Finally, during clinical verification, we can discover relationships between urine biomarkers and disease. This article intends to demonstrate the impact of effective factors (physiological and pharmacological) on potential disease markers in tabular form. We suggest that these proteins be carefully considered in the verification of potential disease markers. This should reduce unnecessary costs of clinical verification. We are looking forward to establishing specific relationships between human diseases and their urinary biomarkers more effectively.
\end{abstract}

urine proteome, physiological factors, pharmacological factors, disease markers

doi: $10.1360 / \mathrm{N} 052017-00157$ 